\title{
Электролюминесценция кремниевых МОП структур с массивами наноостровков $\mathrm{Ge}(\mathrm{Si})$
}

\author{
() В.Б. Шмагин, С.Н. Вдовичев, Е.Е. Морозова, А.В. Новиков, М.В. Шалеев, \\ Д.В. Шенгуров, З.Ф. Красильник
}

Институт фризики микроструктур Российской академии наук, 603950 Нижний Новгород, Россия

Нижегородский государственный университет им. Н.И. Лобачевского, 603950 Нижний Новгород, Россия

E-mail: shm@ipmras.ru

(Получена 27 апреля 2016 г. Принята к печати 10 мая 2016 г.)

В настоящем сообщении представлены результаты экспериментов по наблюдению электролюминесценции из кремниевых структур металл-окисел-полупроводник (МОП) с массивами самоформирующихся наноостровков $\mathrm{Ge}(\mathrm{Si})$ и оксидом алюминия $\mathrm{Al}_{2} \mathrm{O}_{3}$ в качестве изолирующего слоя. Проанализированы изменения в спектрах электролюминесценции МОП структур, вызываемые изменением работы выхода металла. При комнатной температуре наблюдалась интенсивная электролюминесценции наноостровков $\mathrm{Ge}(\mathrm{Si})$, удаленных на расстояние $\sim 50$ нм от интерфейса окисел-полупроводник. Показано, что, выбирая соответствующие параметры полупроводниковой структуры и высоту барьера для инжектируемых носителей, можно управлять спектром излучения МОП структуры.

\section{1. Введение}

В связи с развитием кремниевой нанофотоники и разработкой оптических коммуникационных каналов на основе кремниевых либо гибридных светодиодов и лазеров представляется важным изучение излучательных свойств оптических элементов с инжекцией неосновных носителей из металла в полупроводник. Существенным обстоятельством, стимулирующим исследования в данном направлении, является тот факт, что технология контактов металл-окисел-полупроводник (МОП) полностью совместима с современной КМОП (комплементарной МОП) технологией. Потенциальные преимущества светоизлучающих устройств с МОП контактом, по сравнению с традиционными светодиодами на основе $p-n$ - или $p-i-n$-переходов, связаны с раздельным управлением высотами барьеров для основных и неосновных носителей и возможностью создания „селективных“ контактов, позволяющих блокировать прохождение через контакт нежелательного типа носителей.

Анализируя свойства МОП контактов, выделим наиболее важные для оценки перспектив излучателей с таким контактом. Введение тонкого изолирующего слоя в контакт металл-полупроводник (как правило, речь идет о слое широкозонного оксида толщиной в несколько нм) позволяет устранить „жесткую“ привязку уровня Ферми металла к уровню зарядовой нейтральности (charge neutrality level, CNL) полупроводника, положение которого относительно границ запрещенной зоны полупроводника определяется распределением плотности поверхностных состояний. В кремнии уровень CNL при стандартной обработке поверхности расположен вблизи потолка валентной зоны [1], что существенно ограничивает инжекцию электронов в $p$-Si. Устранение привязки уровня Ферми к уровню CNL позволяет за счет выбора металла с малой работой выхода (Al, Hf,
$\mathrm{Mg}$ ) снижать высоту барьера для электронов и тем самым усиливать их инжекцию в $p$-Si.

Кроме того, использование $h i g h-k$-диэлектриков с высокой диэлектрической проницаемостью и относительно малой шириной запрещенной зоны $\left(\mathrm{HfO}_{2}, \mathrm{ZnO}, \mathrm{Al}_{2} \mathrm{O}_{3}\right)$ позволяет за счет варьирования разрывов зон на границе окисел-полупроводник создавать так называемые „селективные“ контакты, которые блокируют прохождение через МОП контакт основных носителей и тем самым усиливают инжекцию неосновных носителей из металла в полупроводник [2-4].

Первые наблюдения и исследования электролюминесценции (ЭЛ) из кремниевых МОП структур с квантовыми ямами $\mathrm{Ge}(\mathrm{Si})$ и массивами наноостровков были выполнены, по-видимому, исследовательской группой из университета г. Тайбэй (Тайвань). В [5-8] сообщалось о наблюдении при комнатной температуре ЭЛ из МОП структур $\mathrm{Al} / \mathrm{SiO}_{2} / p-\mathrm{Si}$ и $\mathrm{ITO} / \mathrm{SiO}_{2} / p-\mathrm{Si}$ с массивами наноостровков $\mathrm{Ge}(\mathrm{Si})$ и квантовыми ямами, сформированными в процессе CVD (chemical vapor deposition). Внешняя квантовая эффективность „островковой“ ЭЛ из МОП структуры $\mathrm{Al} / \mathrm{SiO}_{2} / p$-Si c 20 слоями наноостровков $\mathrm{Ge}(\mathrm{Si})$ составила $\sim 6 \cdot 10^{-6}$ при температуре $T=340 \mathrm{~K}[8]$. Весьма неожиданным, с нашей точки зрения, выглядит утверждение авторов, что в исследованных ими структурах излучающая область, примыкающая к гетерогранице полупроводник-диэлектрик, весьма узка $(<10$ нм) и ограничена областью аккумуляции основных носителей — дырок [8]. В [9] сообщалось о наблюдении при $T=10 \mathrm{~K}$ ЭЛ из МОП структуры $\mathrm{Al} / \mathrm{SiO}_{2} / p$ $\mathrm{Si}$ с одним слоем островков $\mathrm{Ge}(\mathrm{Si})$, сформированных в процессе молекулярно-пучковой эпитаксии (МПЭ).

Использование $\mathrm{SiO}_{2}$ в качестве диэлектрика, повидимому, связано, с одной стороны, с его широким применением в КМОП технологии и, с другой стороны, с высокой чувствительностью высоты барьера для элек- 
тронов $\left(\Phi_{B n}\right)$ к изменению работы выхода металла $\Phi_{M}$ $\left(S=d \Phi_{B n} / d \Phi_{M} \approx 0.86[10]\right)$. Вместе с тем $\mathrm{SiO}_{2}$, с нашей точки зрения, обладает рядом недостатков, которые могут отрицательно сказаться на излучательных свойствах МОП структур с островками $\mathrm{Ge}(\mathrm{Si})$. К их числу можно отнести большую ширину запрещенной зоны ( $\sim 9$ эВ), трудность поддержания стехиометрии и относительно высокое содержание дефектов в слое $\mathrm{SiO}_{2}$ (в [5-8] отмечалось, что основной механизм токопереноса в МОП структурах с использованием $\mathrm{SiO}_{2}$ - перенос по ловушкам), что связано, по-видимому, с невозможностью использования высоких температур при формировании слоя $\mathrm{SiO}_{2}$ в МОП структурах с массивами наноостровков $\mathrm{Ge}(\mathrm{Si})$.

В настоящем сообщении представлены результаты экспериментов по наблюдению ЭЛ из кремниевых МОП структур с массивами самоформирующихся наноостровков $\mathrm{Ge}(\mathrm{Si})$ и оксидом алюминия $\mathrm{Al}_{2} \mathrm{O}_{3}$ в качестве изолирующего слоя. К недостаткам $\mathrm{Al}_{2} \mathrm{O}_{3}$ следует отнести меньшую величину $S$-фактора $(S \approx 0.63[10])$, к преимуществам - возможность формирования качественных слоев $\mathrm{Al}_{2} \mathrm{O}_{3}$ при комнатной температуре. В работе проанализированы изменения в спектрах ЭЛ МОП структур, вызываемые изменением работы выхода металла. При комнатной температуре наблюдалась интенсивная ЭЛ наноостровков $\mathrm{Ge}(\mathrm{Si})$, удаленных на расстояние $\sim 50$ нм от гетерограницы окиселполупроводник, заметно превышающее глубину области аккумуляции дырок.

\section{2. Методика эксперимента}

Структуры для исследований были выращены методом МПЭ на установке BALZERS UMS-500P. На подложку $\mathrm{Si}(001)$ КДБ-0.1 последовательно осаждались буферный слой $\mathrm{Si}, 5$ слоев наноостровков $\mathrm{Ge}(\mathrm{Si})$, чередующихся с разделительными слоями $\mathrm{Si}$ толщиной 15 нм, затем покровный слой $\mathrm{Si}$. Температура роста составляла $\sim 600^{\circ} \mathrm{C}$, толщина и уровень легирования буферного и покровного слоев варьировались. На рис. 1 приведены схема и зонная диаграмма исследованных структур с омическим и МОП контактами.

Омический контакт формировался на тыльной стороне структуры осаждением алюминия методом магнетронного распыления с последующим отжигом при температуре $450^{\circ} \mathrm{C}$ в течение 5 мин. Исследования фотолюминесценции (ФЛ) и вольт-амперных характеристик $(\mathrm{BAX})$ показали, что такой режим отжига не влияет на фотолюминесцентные свойства островков, но существенно улучшает омические характеристики алюминиевого контакта.

Слой оксида алюминия $\mathrm{Al}_{2} \mathrm{O}_{3}$ формировался поверх покровного слоя $\mathrm{Si}$ окислением предварительно осажденного слоя Al на воздухе при комнатной температуре. Металлические слои, необходимые для формирования верхнего металлического контакта (Al, $\mathrm{Au})$, осаждались

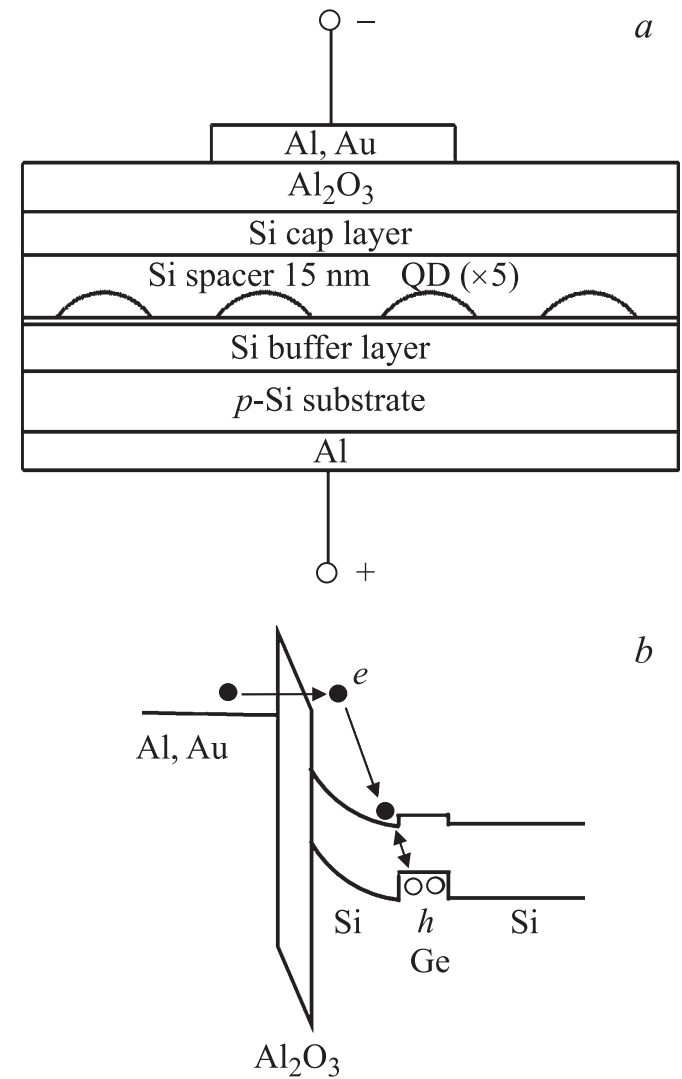

Рис. 1. Схема $(a)$ и зонная диаграмма $(b)$ кремниевой МОП структуры с массивом самоформирующихся наноостровков $\mathrm{Ge}(\mathrm{Si})(\mathrm{QD})$ при отрицательном смещении на металлическом электроде.

магнетронным распылением через маску, в которой были вырезаны круглые отверстия диаметром 1 мм. Далее структура разрезалась на чипы $2 \times 2$ мм.

Исследования спектральных свойств МОП структур в диапазоне 900-1600 нм выполнены с использованием решеточного монохроматора МДР 23 и охлаждаемого приемника InGaAs. Для возбуждения и регистрации спектров ЭЛ использовались импульсный источник тока (длительность импульсов $\sim 4 \mathrm{мc,} \mathrm{частота} \mathrm{повторе-}$ ния $\sim 38$ Гц, плотность тока накачки $\left.\sim 1-10 \mathrm{~A} / \mathrm{cm}^{2}\right)$ и синхронное накопление сигнала.

\section{3. Результаты и их обсуждение}

На рис. 2 приведены спектры ЭЛ и прямые ветви BAX $I(U)$ двух образцов одной и той же структуры, различающихся металлом, используемым в МОП контакте: $\mathrm{Al} / \mathrm{Al}_{2} \mathrm{O}_{3} / p-\mathrm{Si}$ (образец \#1) и $\mathrm{Au} / \mathrm{Al}_{2} \mathrm{O}_{3} / p-\mathrm{Si}$ (образец \#2). Толщины буферного и покровного слоев $\mathrm{Si}$ составили 200 и 50 нм соответственно, концентрация носителей заряда (дырок) в покровном и буферном слоях $p \sim 10^{16} \mathrm{~cm}^{-3}$. Каждый из спектров представлен пиком краевой ЭЛ кремния ( 1140 нм) и пиком „островковой“ ЭЛ $(\sim 1550 \mathrm{Hм})$. 

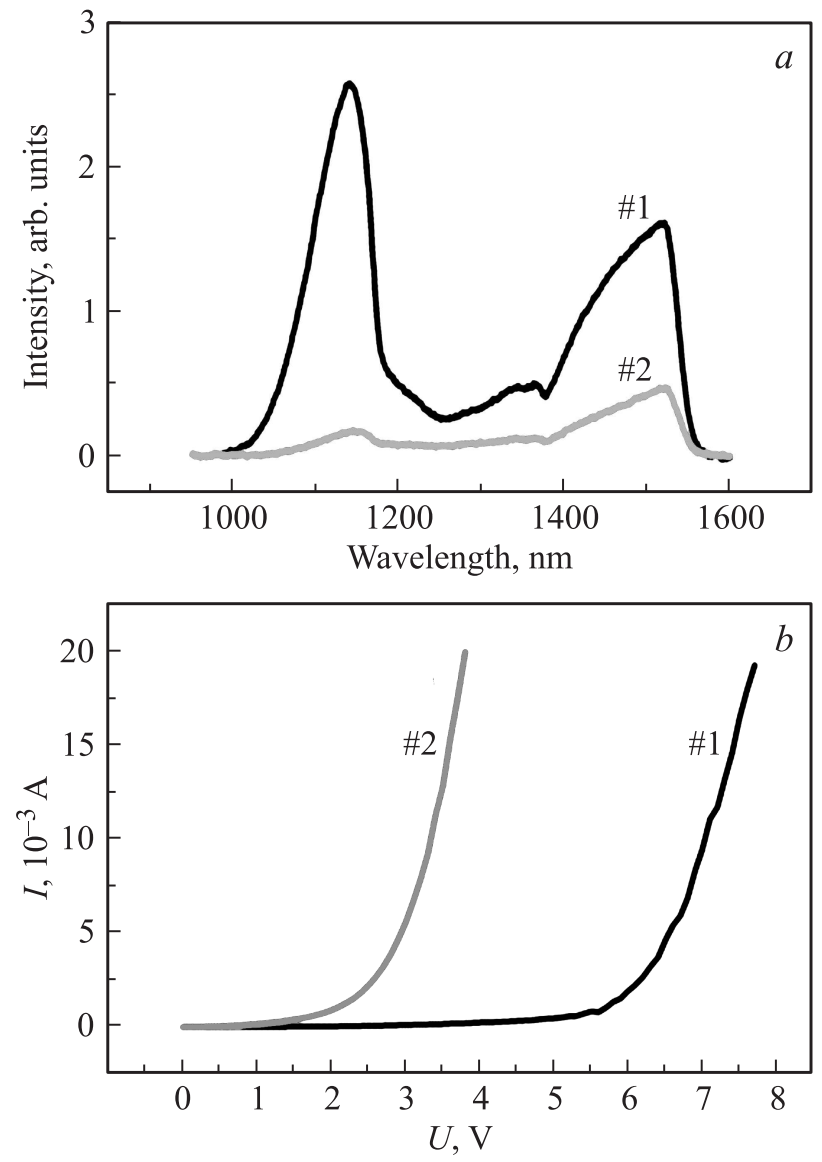

Рис. 2. Спектры ЭЛ $(a)$ и прямые ветви $\mathrm{BAX}(b)$ образцов $\mathrm{Al} / \mathrm{Al}_{2} \mathrm{O}_{3} / p-\mathrm{Si}$ (\#1) и $\mathrm{Au} / \mathrm{Al}_{2} \mathrm{O}_{3} / p-\mathrm{Si}$ (\#2). Покровный слой: $\sim 50$ нм, $p \sim 10^{16} \mathrm{~cm}^{-3}$; буферный слой: $\sim 200$ нм, $p \sim 10^{16} \mathrm{~cm}^{-3}$. Ток накачки $20 \mathrm{MA}$, температура $300 \mathrm{~K}$. Пик „островковой“ ЭЛ обрезан с длинноволновой стороны InGaAsприемником.

Прежде всего отметим, что сам факт наблюдения ЭЛ наноостровков $\mathrm{Ge}(\mathrm{Si})$ в МОП структуре с толщиной покровного слоя $\sim 50$ нм находится в явном противоречии с выводами [8] и говорит о том, что проникновение электронов в полупроводниковые слои МОП структуры простирается в область электронейтральности полупроводниковой структуры на значительную глубину, $\sim(50-100)$ нм.

Сравнение ВАХ образцов \#1 и \#2 показывает, что, изменяя работу выхода металла, можно достаточно эффективно управлять высотой барьера для основных носителей, т.е. уровень Ферми металла не закреплен жестко на поверхностных состояниях полупроводника (даже при толщине диэлектрического слоя МОП структуры $\sim 2$ нм). При замене алюминия золотом с большей работой выхода (работа выхода $\mathrm{Al} / \mathrm{Al}_{2} \mathrm{O}_{3}$ и $\mathrm{Au} / \mathrm{Al}_{2} \mathrm{O}_{3}$ составляет 3.9 и $5.1 \ni \mathrm{B}$ соответственно [10]) барьер для основных носителей (дырок) уменьшается, и ВАХ сдвигается в сторону меньших напряжений (рис. 2,b). При этом, во-первых, увеличивается барьер для неосновных носителей (электронов), инжектируемых из металла в полупроводник, во-вторых, заданная величина тока накачки (20 мА, см. рис. 2,a) достигается при меньшем напряжении смещения и, следовательно, при меньшей величине изгиба зон (см. рис. $1, b)$. Оба фактора ослабляют инжекцию электронов в $p$-Si и тем самым интенсивность ЭЛ, что и наблюдается на рис. 2, $a$. Преобладание краевой ЭЛ над „островковой“ в с спектре образца \#1 объясняется тем, что в этом образце вследствие более сильной инжекции излучающая область простирается на бо́льшую глубину по сравнению с образцом \#2 и в процесс люминесценции вовлекается заметная часть буферного Si-слоя.

Более контрастным преобладание краевой ЭЛ над „островковой“ при увеличении работы выхода металла наблюдается в структуре с островками $\mathrm{Ge}(\mathrm{Si})$, в которой толщина покровного слоя уменьшена до $10 \mathrm{Hм}$, а уровень легирования буферного Si-слоя увеличен до $10^{18} \mathrm{~cm}^{-3}$ (рис. 3). При замене металла в МОП контакте с Al на $\mathrm{Au}$ меняется сам источник излучения. Если в спектре ЭЛ образца \#3 $\left(\mathrm{Al} / \mathrm{Al}_{2} \mathrm{O}_{3} / p\right.$ - $\left.\mathrm{Si}\right)$ преобладает излучение буферного Si-слоя, то в спектре ЭЛ образца \#4 $\left(\mathrm{Au} / \mathrm{Al}_{2} \mathrm{O}_{3} / p\right.$-Si) преобладает „островковая“ ЭЛ. Таким образом, выбирая параметры структуры и высоту барьера для инжектируемых носителей (варьируя толщину и уровень легирования покровного и буферного слоев, работу выхода металла, толщину диэлектрика и разрыв зоны проводимости на гетерогранице окиселполупроводник), можно управлять спектром излучения диодной МОП структуры.

Особенностью образцов \#3 и \#4 является различный уровень легирования покровного $\left(10^{16} \mathrm{~cm}^{-3}\right)$ и буферного $\left(10^{18} \mathrm{~cm}^{-3}\right)$ слоев $\mathrm{Si}$, что позволило разделить вклады покровного и буферного слоев в краевую ЭЛ кремния и тем самым оценить глубину проникновения инжектируемых электронов в полупроводниковую структуру. На рис. 4 приведены спектры краевой (кремниевой) ЭЛ образцов \#2 и \#4 с одинаковым уровнем легирования покровного слоя $\left(p \sim 10^{16} \mathrm{~cm}^{-3}\right)$ и различными уров-

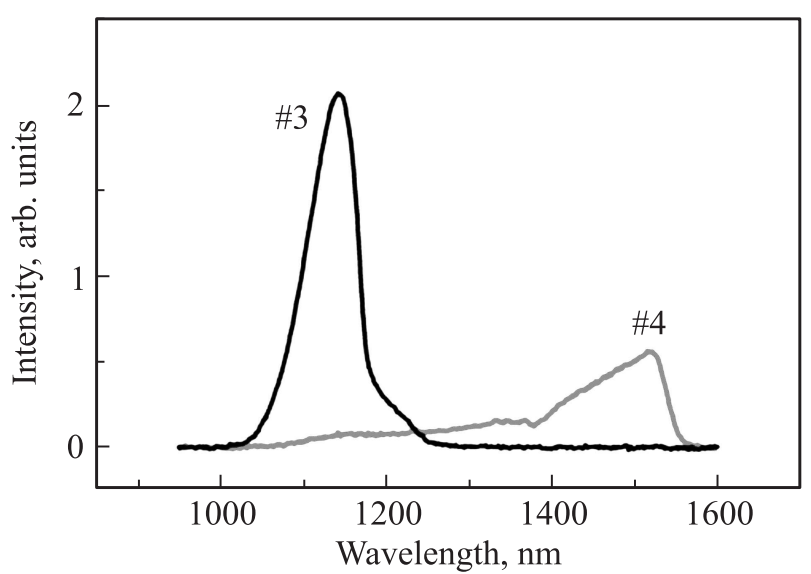

Рис. 3. Спектры ЭЛ образцов $\mathrm{Al} / \mathrm{Al}_{2} \mathrm{O}_{3} / p-\mathrm{Si}(\# 3)$ и $\mathrm{Au} / \mathrm{Al}_{2} \mathrm{O}_{3} /$ $p$-Si (\#4). Покровный слой: $\sim 10$ нм, $p \sim 10^{16} \mathrm{~cm}^{-3}$; буферный слой $\sim 200$ нм, $p \sim 10^{18} \mathrm{~cm}^{3}$. Ток накачки 30 (\#3) и $60 \mathrm{MA}(\# 4)$, температура $300 \mathrm{~K}$. 


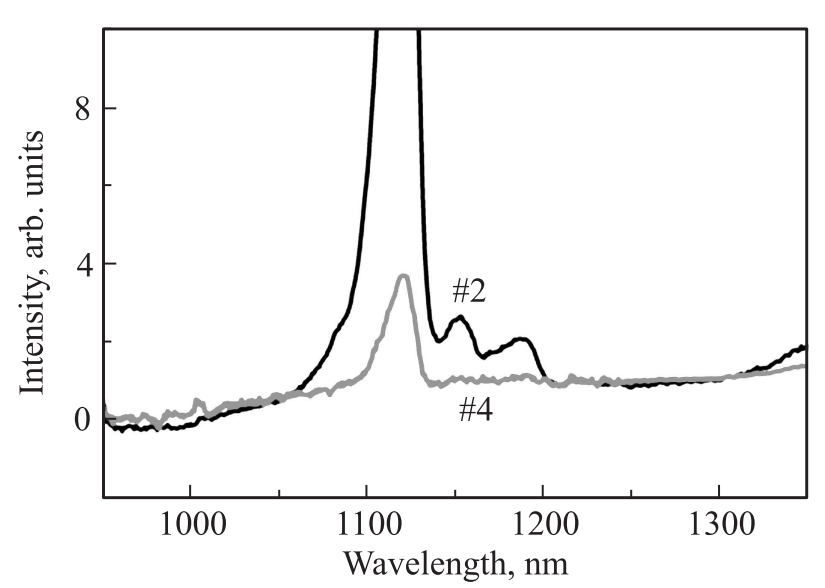

Рис. 4. Спектры краевой ЭЛ структуры $\mathrm{Au} / \mathrm{Al}_{2} \mathrm{O}_{3} / p-\mathrm{Si}$ с уровнем легирования буферного $\mathrm{Si-cлоя} \sim 10^{16}$ (\#2) и $\sim 10^{18} \mathrm{~cm}^{-3}(\# 4)$. Ток накачки 30 (\#2) и $60 \mathrm{MA}$ (\#4), температура $77 \mathrm{~K}$.

нями легирования буферного Si-слоя $\left(p \sim 10^{16} \mathrm{~cm}^{-3}\right.$ в образце \#2 и $p \sim 10^{18} \mathrm{~cm}^{-3}$ в образце \#4). В спектре образца \#2 хорошо видны фононные повторения межзонного перехода, в то время как в спектре образца \#4 они отсутствуют, что характерно для высоколегированного кремния. Отсюда следует, что источником краевой ЭЛ в образце \#4 является большей частью высоколегированный буферный слой $\mathrm{Si}$, удаленный от интерфейса окисел-полупроводник на весьма значительное расстояние $\sim 85$ нм. Таким образом, исследование спектров ЭЛ (как краевой, так и „островковой“) кремниевых МОП структур с массивами наноостровков $\mathrm{Ge}(\mathrm{Si})$ позволяет утверждать, что глубина проникновения инжектируемых электронов в полупроводниковые слои МОП структур достаточно велика ( 50-100 нм) и не ограничена областью аккумуляции основных носителей.

\section{4. Заключение}

Установлено, что излучающая область в кремниевых МОП структурах с наноостровками $\mathrm{Ge}(\mathrm{Si})$ простирается в область электрической нейтральности структуры на глубину по крайней мере 50-100нм. Показано, что, выбирая соответствующие параметры полупроводниковой структуры и высоту барьера для инжектируемых носителей (варьируя толщину и уровень легирования покровного и буферного слоев, работу выхода металла, толщину диэлектрика и разрыв зоны проводимости на интерфейсе окисел-полупроводник), можно оптимизировать спектр излучения диодной МОП структуры с наноостровками $\mathrm{Ge}(\mathrm{Si})$ для целей телекоммуникации.

Работа выполнена при финансовой поддержке РФФИ (грант № 15-02-05272) и программ РАН.

В работе использовано оборудование ЦКП „Физика и технология микро- и наноструктур“.

\section{Список литературы}

[1] Э.Х. Родерик. Контакты металл-полупроводник (М., Радио и связь, 1982).

[2] K.-Y. Tse, J. Robertson. Phys. Rev. Lett., 99, 086805 (2007).

[3] T. Arguirov, Ch. Wenger, M. Lukosius, T. Mchedlidze, M. Reiche, M. Kittler. Phys. Status Solidi C, 8, 1302 (2011).

[4] R. Islam, G. Shine, K.C. Saraswat. Appl. Phys. Lett., 105, 182103 (2014).

[5] M.H. Liao, C.Y. Yu, T.H. Guo, C.H. Lin, C.W. Liu. IEEE Electron Dev. Lett., 27, 252 (2006).

[6] M.H. Liao, C.H. Lee, T.A. Hung, C.W. Liu. J. Appl. Phys., 102, 053520 (2007).

[7] T.H. Cheng, M.H. Liao, L. Yeh, T.L. Lee, M.S. Liang, C.W. Liu. J. Appl. Phys., 103, 016103 (2008).

[8] M.H. Liao. Appl. Phys. Lett., 94, 241908 (2009).

[9] S. Das, S. Manna, R.K. Singha, R. Aluguri, S.K. Ray. J. Appl. Phys., 113, 063101 (2013).

[10] Y.Ch. Yeo, Ts.J. King, Ch. Hu. J. Appl. Phys., 92, 7266 (2002).

Редактор Л.В, Шаронова

\section{Electroluminescence from MIS silicon based light emitters with arrays of nanoislands $\mathrm{Ge}(\mathrm{Si})$}

\author{
V.B. Shmagin, S.N. Vdovichev, E.E. Morozova, \\ A.V. Novikov, M.V. Shaleev, D.V. Shengurov, \\ Z.F. Krasilnik \\ Institute for Physics of Microstructures, \\ Russian Academy of Sciences, \\ 603950 Nizhny Novgorod, Russia \\ Lobachevskii Nizhny Novgorod State University, \\ 603950 Nizhny Novgorod, Russia
}

\begin{abstract}
We report on electroluminescence from silicon based metal-insulator-semiconductor (MIS) diodes with arrays of selfassembled $\mathrm{Ge}(\mathrm{Si})$ nanoislands. Aluminum oxide $\left(\mathrm{Al}_{2} \mathrm{O}_{3}\right)$ was used as an insulator material in MIS contact. Variations in electroluminescence spectra caused by change in the metal work function are examined. The intense electroluminescence from $\mathrm{Ge}(\mathrm{Si})$ nanoislands localized at the distance of $50 \mathrm{~nm}$ from the insulator-semiconductor interface was observed at room temperature. The emission spectrum is found to be controlled by choosing the design of semiconductor structure and the barrier height for injected carriers.
\end{abstract}

